\title{
НЕКОТОРЫЕ ОСОБЕННОСТИ ВЛИЯНИЯ ГЛОБАЛИЗАЦИИ НА УПРАВЛЕНИЕ БИЗНЕСОМ
}

\section{(C) 2021 Репина Юлия Александровна}

кандидат социологических наук, доцент кафедры «Цифровая экономика и управление качеством» Казанский инновационный университет им. В.Г. Тимирясова, Россия, Казань

В статье приводится краткий обзор влияния глобализации на управление бизнесом на современном этапе. Последние два десятилетия стали свидетелями великой революции с точки зрения технологических инноваций, особенно в области связи и транспорта. Это продвижение в значительной степени сблизило страны и рынки. Экономический процесс становится все более интернационализированным в ряде сфер, таких как коммуникации, торговля, финансы, производство и т.д. [2] Новые технологии ускоряют мобильность экономических единиц и чувствительность рынков, а также общества, тем самым ещё больше увеличивая глобализацию мировой экономики. Это послужило причиной перехода к идее глобальной свободной торговли, реализованной через Всемирную торговую организацию.

В результате глобализации произошло перемещение отраслей из их старых центров в богатой стране с высокими затратами на рабочую силу в полностью новую страну с изобилием дешевой рабочей силы. Раньше труд оставался важным фактором производства. Но с технологическим прорывом потребность в человеческом труде больше не требуется, что вызывает неисчислимый рост безработицы и неполной занятости [1]. В то время как рабочие в развитых странах опасаются потерять работу, рабочие в развивающихся странах надеются увидеть расширение возможностей трудоустройства. Но концепция свободного рынка вынуждает правительства стран третьего мира снижать затраты на социальное обеспечение и общественное благосостояние, что приводит к сокращению перспектив занятости. Эти социальные и политические последствия глобализации ощущаются во всем мире, но более очевидны в странах третьего мира. Еще один важный эффект глобализации трудовая миграция.

Ключевые слова: глобализация в экономике, рабочие места, бизнес

Рабочие места во всем мире сильно изменились за последнее десятилетие. Организации стали более глобальными, а сотрудники более разнообразны, чем когда-либо прежде. Организационные структуры менее иерархичны и более совместимы. И сегодняшние сетевые офисы полны технологических отвлекающих факторов, которые были бы немыслимы для менеджера 20-го века.

Можно отметить, глобализация указывает на все усилия по превращению мирового глобального сообщества в одну деревню. Товары, которые можно было найти только в западных странах, теперь можно найти по всему миру. Теперь слаборазвитые районы могут пользоваться преимуществами научных достижений и промышленного прогресса, доступными в развитых странах, для улучшения и роста своих территорий.

Из-за глобализации мировая экономика становится все более интегрированной, напри- мер, мобильные телефоны и Интернет сблизили людей. Мир становится все меньше. Работа может быть передана на аутсорсинг в любую часть мира, где есть подключение к Интернету, поскольку благодаря улучшениям транспортной инфраструктуры можно быстро добраться до места назначения.

Глобализацию также можно определить как непрерывный процесс, посредством которого региональные экономики, общества и культуры становятся интегрированными через глобальную сеть связи и торговли. Процесс глобализации включает в себя ряд факторов: быстрое развитие технологий, делающих возможными глобальные коммуникации, политические события, такие как падение коммунизма, и развитие транспорта, которое делает поездки более быстрыми и частыми. Это создает большие возможности для развития компаний с открытием дополнительных рынков, позволяет лучше согласовывать потребности клиентов в результате 
роста общих культурных ценностей и обеспечивает более высокую конкурентоспособность с более низкими эксплуатационными расходами в других странах и доступом к новому сырью. ресурсы и инвестиционные возможности.

Благодаря глобализации людям из разных стран предоставляются рабочие места в глобальном масштабе. Это создало концепцию аутсорсинга. Развитые страны предпочитают предоставлять работу развивающимся странам с низкими затратами. Такая работа, как поддержка клиентов, разработка программного обеспечения, бухгалтерский учет, маркетинг и страхование, влияние глобализации на управление бизнесом в развивающихся странах.

«Я знаю, что глобализация также привела к множеству негативных последствий, но я считаю, что всегда лучше смотреть в будущее с оптимизмом и надеждой. Надеюсь, завтра мы сможем минимизировать или даже искоренить злые силы, которые создают дурную репутацию глобализации. Таким образом, мы сможем двигаться вперед в мире и согласии» [1].

Что касается сокращения бедности, глобализация сыграла роль в сокращении бедности в развивающихся странах. На самом деле в большинстве развитых стран наблюдалось сокращение бедности в части их жизни за чертой бедности, включая такие быстроразвивающиеся страны, как Китай, Индия, Вьетнам. В то время как в других странах, например в Африке к югу от Сахары, наблюдается противоположная тенденция [2].

Работы предоставляются развивающимся странам, таким как Индия. Следовательно, страна, которой дается работа, получает удовольствие от ее получения. Это дало возможность инвестировать в развивающиеся рынки и задействовать имеющиеся там таланты. В развивающихся странах часто не хватает капитала, что препятствует росту отечественных компаний и, следовательно, занятости. В таких случаях из-за глобального характера бизнеса люди из развивающихся стран также могут получить возможности для получения оплачиваемой работы [3]. Это мощная сила, которая движет миром к сходящейся общности. Он пролетаризировал связь, транспорт и путешествия. Люди из разных мест и повсюду хотят всего того, о чем они слышали, видели или испытали с помощью технологий. Организации через свое руководство могут получать знания из разных мест мира, которые мо- гут быть использованы в организации.

Телевидение и средства массовой информации сыграли большую роль во влиянии на восприятие мира, от относительно небольшого национального единства и реальности до глобального рынка и международных интересов. По мере того, как транснациональные корпорации создают дочерние компании в новых местах, они передают ноу-хау от материнской компании местному подразделению. Знания передаются от одного подразделения к другому, и вся организация получает выгоду от деятельности по развитию. Один из способов, используемых организациями для передачи знаний,- это перемещение персонала внутри транснациональных корпораций. Это создает банк знаний о работе в различных ситуациях с людьми из разных культур, и это представляет собой запас знаний, который можно развивать и использовать на благо организации [4].

С точки зрения глобализации, есть как положительные, так и отрицательные эффекты. Это расширило доступ к университетам высшего образования и уменьшило разрыв в знаниях в развивающихся странах, оно также имеет негативные аспекты, которые могут серьезно угрожать университетам в этих странах [3]. С этой точки зрения, это принесло больше положительных результатов в развивающиеся страны за счет расширения доступа к высшим учебным заведениям. Сегодня вы можете беспрепятственно перемещаться в поисках лучших учебных заведений мира, в том числе и в развивающихся странах. Это связано с увеличением выпуска в средних школах, более широким участием женщин в высшем образовании, растущим спросом частного сектора на выпускников и непомерными расходами на получение образования в зарубежных странах, особенно на севере [5].

Несмотря на негативные последствия глобализации, у нее есть и положительная сторона. Одним из наиболее значительных эффектов, которые он оказал на развивающиеся страны, является торговля. Раньше люди обменивали товары на товары или услуги на услуги, но теперь люди могут обменивать товары на деньги. В основном это происходит через международную торговлю, когда люди экспортируют и импортируют товары внутри страны. Глобализация привела к снижению затрат в торговле внутри земного шара. Это привело к снижению налога на ввоз товаров. 
Согласно экономической теории, внешняя торговля в принципе выгодна любой вовлеченной стране [1]. Международное разделение труда более эффективно распределяет ресурсы, тем самым повышая экономическое благосостояние всех стран, участвующих во внешней торговле, в долгосрочной перспективе.

Иностранные инвестиции - прямой результат глобализации. Иностранные инвестиции всегда приветствуются, поскольку они предоставляют стране ресурсы, капитал и технологии, которые будут поддерживать экономическое развитие принимающей страны. Это улучшает занятость как прямо, так и косвенно. Увеличивает экспорт в страну и тем самым улучшает текущий счет и, следовательно, способствует погашению внешнего долга. Однако это вызывает некоторые критические замечания за то, что ведет к слишком большому иностранному контролю [2].

Развивающиеся страны могут использовать общую или конкретную промышленную и торговую политику для более или менее благоприятного отношения к прямым иностранным инвестициям, капиталу и иностранным туристическим услугам. Они могут прямо или косвенно влиять на свое участие в экономической деятельности в мире [3].

Негативные последствия глобализации для управления бизнесом в развивающихся странах. Глобализация - это инструмент, приносящий пользу всем слоям человечества. Мы не можем игнорировать негативные последствия, которые он оказывает на развивающиеся страны.

Глобализация является причиной мировой безработицы, хотя она принесла некоторые рабочие места. Несмотря на то, что это открыло возможности для трудоустройства во всем мире, но все же виновата нынешняя ситуация. «Это правда, что глобальная экономическая интеграция и увеличение количества поездок привели к повышению конкурентоспособности на национальном уровне и уровне предприятий, вынуждая производителей искать способы сокращения затрат, повышения эффективности и повышения производительности» [4].

«Наиболее важным фактором, определяющим уровень занятости в период 1980-2000 годов, была национальная или региональная макроэкономическая политика, которая осуществлялась и поддерживалась. Кроме того, страны, проводившие либеральные макроэкономические реформы, проводили политику, способствующую гибким рынкам труда и практике занятости, децентрализованным системам производственных отношений. и разумное принуждение к труду. С другой стороны, страны с трудовым законодательством, нормативными актами и политикой испытали более высокий уровень занятости, потому что они были не в состоянии привлечь и сохранить столько новых рабочих мест» [6].

Например, Индонезия столкнулась с безработицей и бедностью, которые выросли до уровней, невиданных за последние два десятилетия, состояние здоровья ухудшилось, а природная среда деградировала [5].

Глобализация привела к распространению западной культуры и влияния за счет местной культуры в развивающихся странах, таких как Африка. Большинство людей сейчас в развивающихся странах копируют то, что делают люди в развитых странах. Таким образом, это похоже на то, что они игнорируют свою собственную культуру и практикуют западную культуру [7]. Например, стиль одежды и пищевые привычки, язык. Все это может так или иначе повлиять на менеджмент, вызвать недопонимание из-за языкового барьера. Средние тарифные ставки по-прежнему высоки во многих развивающихся странах, в том числе в некоторых, недавно осуществивших торговые реформы. Пример, Индия. Торговая политика продолжает оставаться важным аспектом глобализации, по крайней мере, в некоторых развивающихся странах с низкими доходами.

\section{Библиографический список}

1. Каркинбаева Ш.И., Ауезова К. Т., Машкалова Б. К., Бакбергенова А.Д. Влияние глобализации на управление бизнесом // [электронный ресурс]: режим доступа: https://articlekz.com/en/article/21127

2. R. K. Mirsa Глобализация: влияние и последствия глобализации// [электронный ресурс]: режим доступа: https://www.yourarticlelibrary.com/essay/globalization-impact-and-consequences-of-globalization/40291

3. Прабхакар Пиллаи, Возможности трудоустройства в странах разработки

4. Надер Асгари и Альф Валле, Межкультурный менеджмент в развитых странах, том 9, 2007. 
5. Пясецки Р. и Вольницки М., Ситуация с безработицей в развивающихся странах, Международная торговля в развитых странах, Отсутствие безопасности рабочих мест в развитых странах, эволюция экономики развития и глобализация, т. 31 № 3,

6. Мохамедбхай Г., Влияние глобализации, глобализации и ее последствий для университетов в развивающихся странах,

7. Камоче К. (1996), цитируется в Kidger PJ, Структура управления транснациональных корпораций в ответ на глобализацию Том 24 № 1, 2008 69-85. 